\title{
Multi-trait animal model estimation of genetic parameters for linear type and gait traits in the Belgian warmblood horse
}

\author{
M. Rustin ${ }^{1,2}$, S. Janssens ${ }^{1}$, N. Buys ${ }^{1} \&$ N. Gengler ${ }^{2,3}$ \\ 1 Division of Gene Technology, Department of Biosystems, KULeuven, Kasteelpark Arenberg, Heverlee, Belgium \\ 2 Animal Science Unit, Gembloux Agricultural University, Passage des Déportés, Gembloux, Belgium \\ 3 National Fund for Scientific Research, Brussels, Belgium
}

\author{
Keywords \\ conformation; gait; genetic parameters; linear \\ scoring; warmblood horse. \\ Correspondence \\ M. Rustin, Animal Science Unit, Gembloux \\ Agricultural University, Passage des Déportés 2, \\ B-5030 Gembloux, Belgium. \\ Tel: +32(0)81 622358 ; \\ Fax: +32(0)8162 21 15; \\ E-mail: rustin.m@hotmail.com \\ Received: 22 April 2008; \\ accepted: 19 December 2008
}

\begin{abstract}
Summary
Genetic parameters for the height at withers, 27 linear type and six linear gait traits were estimated for the Belgian warmblood horse. Observations on 987 mares, mostly 3 years old, were analysed using a multi-trait animal model. The statistical model included appraiser, age and location (date $\times$ place of appraisal) as fixed effects. Genetic parameters were estimated using a canonical transformation and an expectation-maximization restricted maximum likelihood algorithm with an additional deceleration step. Estimates of heritability for the 33 linear traits were between 0.15 and 0.55 . Heritability of the height at withers was $0.34 \pm 0.06$. Estimated genetic correlations ranged from -0.60 to 0.98 with an average SE of 0.10. The highest positive correlations were found among traits of walk and among traits of trot. Volume and the quality of legs were the most negatively correlated. Estimated genetic parameters indicated that the linear scoring system is a valuable tool to assess conformation. The full (co)variance matrix is now available for breeding value estimation to support selection for conformation and gaits.
\end{abstract}

\section{Introduction}

The Belgian warmblood horse (BWP) is a saddle horse, used primarily in show jumping and dressage at recreational and international level. The breeding organization of the BWP has introduced conformation and gaits recording in its breeding program because of their influences on horse abilities. In fact, conformation and gaits are important for aesthetics, wellness, durability and functionality of horses (Forest 1996). The success in many types of horse shows depends partly on these characteristics. Conformation and gaits have also been proposed as indirect indicators of performance capacity, since heritability coefficients of conformation traits were often higher than those found for performance traits (Saastamoinen \& Barrey 2000).

Therefore, functional conformation and gaits are important selection criterions in horse breeding. This is reflected in the breeding objective of the BWP which mentions the achievement of a correctly-built horse with a rectangular frame, big outlines and good basic paces.

Conformation and gaits of the BWP mares are appraised in two ways: the conformation and gaits contests (i.e. halter presentation) and a linear scoring system.

In the conformation and gait contests, mares are ranked by a jury based on aesthetics ('expressiveness', 'brightness', etc.) and on functional (correctness, etc.) aspects of type, legs, walk and trot. This system has two important drawbacks, namely the fact that conformation and gaits are appraised in a global manner and that preferences of judges play a role.

Linear scoring could improve on this because body and gaits are subdivided into several distinct traits, assessed separately. Each trait of the horse is scored 
on a linear scale between the two biological extremes (Mawdsley et al. 1996). By assessing traits individually rather than in combination and by describing rather than evaluating, this method easily reveals differences between animals (Koenen et al. 1995). A linear scale can also be considered as a continuous scale. Therefore, this kind of traits can be analysed by a linear mixed-model which is nowadays the standard tool to estimate unbiased breeding values.

Even if linear scoring is used less in horses than in other species like cattle; genetic parameters for linear traits have already been reported in other horse breeds. Using a derivative-free restricted maximum likelihood algorithm and an animal model, Koenen et al. (1995) estimated genetic parameters for the linear scoring of the Dutch warmblood riding horse. Heritabilities, obtained in univariate analyses, ranged between 0.09 and 0.28. Genetic correlations within four trait groups were estimated using bivariate models and varied between -0.69 and 0.98. Samoré et al. (1997), working with the Haflinger Horse, found higher heritabilities, using a multi-trait animal model and an expectation-maximization restricted maximum likelihood algorithm. Values were between 0.02 and 0.53 . Genetic correlations (within 10 groups of traits) ranged between -0.32 and 0.99 . Sampling errors for the estimates of heritability or genetic correlations were not available for these studies. Nevertheless, Van Bergen \& Van Arendonk (1993) have reported standard errors from 0.04 to 0.07 for heritabilities varying between 0.10 and 0.39 (data on Shetland ponies).

The objective of this research is to estimate genetic parameters (heritabilities and genetic correlations) for linear type traits in the BWP horse population as the necessary first step to develop a genetic evaluation system.

\section{Materials and methods}

\section{Scoring system and data}

Linear scoring was introduced by the BWP studbook in 2003. During the assessment, the height at withers is measured and 33 linear traits are scored. Description of the traits is given in Table 1. Of these traits, 17 refer to type, 10 to legs and feet and six to gaits. Linear traits are scored between -20 and 20, these endpoints corresponding theoretically to biological extremes in the BWP population. Scores between the two extremes are multiples of 5 . The 0 of this scale corresponds to the theoretical mean of each linear trait in the BWP population. Descriptive statistics and test of normality were conducted using the Univariate procedure of SAS software (SAS 1985).

From 2003 to 2007, 1215 mares have been classified by 15 classifiers at 28 locations. Mares are scored only once, when they are 3 or 4 years old. Only very few mares aged over 4 years have been recorded. Most horses were between 3 and 3.5 years old (only $8 \%$ of the 1215 mares were over 3.5 years). Mares were classified in seven age classes (Table 2). Six mares aged over 44 months were not included in the set for estimation of variance components. The number of mares varied between 5 and 372 per appraiser and between 1 and 39 per location of assessment. For the estimation of variance components, a minimum of three records per date *location of assessment was set.

\section{Statistical model}

In the present study, the following multi-trait animal model was used to describe the data:

$$
\begin{array}{r}
y=\left(S \otimes I_{t}\right) \text { datloc }+\left(H \otimes I_{t}\right) \text { age } \\
+\left(F \otimes I_{t}\right) \text { app }+\left(Z \otimes I_{t}\right) a+e
\end{array}
$$

$y$, the vector of records; datloc, the vector for the combined fixed effect of the date and the location of assessment (1-94); age, the vector for fixed effect of the age (1-6); app, the vector for fixed effect of appraiser (1-15); $a$, the vector for animal random effect and $e$, for random residual effect. $S, H, F, Z$ were the common incidence matrices for all traits that associate datloc, age, app and $a$, with $y$ and $I_{\mathrm{t}}$ was an identity matrix for the traits ' $\mathrm{t}$ '.

These fixed effects included in the model were found to be significant for most traits $(p<0.05)$ in a preliminary least squares analysis with the general linear models procedure of SAS (SAS 1985).

\section{(Co) variance components estimation}

Estimates of variance components were obtained by a multi-trait REML procedure following a method developed by Misztal et al. (1995) for the analysis of linear scores in dairy cattle (Gengler et al. 1997). The method consists of a canonical transformation and an expectation-maximization REML algorithm (EMREML) with an additional deceleration step. The canonical transformation reduces the computing effort by transforming the 34 correlated traits to 34 uncorrelated traits. Therefore, complexity of the 
Table 1 Description of the linear scoring system for Belgian warmblood horses

\begin{tabular}{|c|c|c|c|}
\hline \multirow[b]{2}{*}{ Traits } & \multirow[b]{2}{*}{ Definition } & \multicolumn{2}{|l|}{ Scale } \\
\hline & & -20 & 20 \\
\hline \multicolumn{4}{|l|}{ Type } \\
\hline 1. Frame & The shape of the body (ratio of body length to body height) & Square & Rectangle \\
\hline 2. Condition & General muscularity and overweight & Poor & Heavy \\
\hline 3. Head & Size of the head, distance between top of the head and the mouth & Small & Tall \\
\hline 4. Head neck connection & Length of the junction between the poll and the throat latch & Light & Heavy \\
\hline 5. Length of neck & Distance between the beginning of the withers and the top of the head & Short & Long \\
\hline 6. Muscularity of neck & Development of the neck & Poor & Heavy \\
\hline 7. Orientation of neck & Angle formed by the neck and the head & Vertical & Horizontal \\
\hline 8. Height of the withers & Height between the highest and the lowest point of the withers & Flat & Prominent \\
\hline 9. Length of withers & Length of the line formed between the highest and the lowest point of the withers & Short & Long \\
\hline 10. Orientation shoulders & Angle between the corner of the crest of the shoulder and an horizontal axis & Straight & Sloping \\
\hline 11. Length of shoulders & Distance between the top of the shoulder-blade and the breast & Short & Long \\
\hline 12. Length of back & Distance between the end of the withers and the beginning of the loins & Short & Long \\
\hline 13. Back force & Form of the upper line & Deep & Straight \\
\hline 14. Loins & Form of the line formed by the loins & Weak & Straight \\
\hline 15. Slope of croup & $\begin{array}{l}\text { Angle formed by the line going from upper side of the haunch to the point } \\
\text { of the buttock and an horizontal axe }\end{array}$ & Straight & Sloping \\
\hline 16. Length of croup & Distance from front side of the haunch to rear side of the point of the buttock & Short & Long \\
\hline 17. Muscularity of hind legs & Muscularity of hind legs above the hock & Poor & Heavy \\
\hline \multicolumn{4}{|l|}{ Limbs } \\
\hline 18. Position of forelegs 1 & $\begin{array}{l}\text { Position of leg relative to a straight line passing trough the canon bone } \\
\text { and the forearm (side view) }\end{array}$ & In roe-deer & Sunken \\
\hline 19. Position of forelegs 2 & Seen from the front, $\mathrm{O}$ or $\mathrm{X}$ position formed by the legs & Flemish & French \\
\hline 20. Position of hind legs & Angle formed by the hock & Sickle-hocked & Straight \\
\hline 21. Position of hocks & Seen from the back, $\mathrm{O}$ or $\mathrm{X}$ position formed by hind legs & Outside & Inside \\
\hline 22. Volume of hocks & Volume and quality of hocks & Light & Heavy \\
\hline 23. Form of hoof & Form of the hoof & Narrow & Broad \\
\hline 24. Position of pasterns & Angle between pasterns and an horizontal axis & Weak & Straight \\
\hline 25. Heels & Distance from the coronet to the front of the foot & Low & Higher \\
\hline 26. Volume of legs & Volume of legs in proportion of the rest of the body & Light & Heavy \\
\hline 27. Quality of legs & Contour of articulation & Blurred & Lean \\
\hline \multicolumn{4}{|l|}{ Gaits (walk + trot) } \\
\hline 28. +31 . Stride length & Length of step & Short & Long \\
\hline 29. +32. Impulsion & Place of hind legs under the body during movements & Lack of power & Powerful \\
\hline 30. +33. Suppleness & Transmission of movement to the body & Stiff & Supple \\
\hline
\end{tabular}

Table 2 Number of linearly scored Belgian warmblood-horses by age class and by year of appraisal

\begin{tabular}{ll}
\hline Year & Number of records \\
\hline 2003 & 201 \\
2004 & 259 \\
2005 & 264 \\
2006 & 254 \\
2007 & 237 \\
\hline
\end{tabular}

Age class

\begin{tabular}{lr}
\hline age $\leq 36$ months & 76 \\
36 <age $\leq 38$ months & 406 \\
38 <age $\leq 40$ months & 481 \\
$40<$ age $\leq 42$ months & 150 \\
42 <age $\leq 44$ months & 17 \\
44 <age $\leq 48$ months & 6 \\
48 months <age & 79
\end{tabular}

multi-trait analysis decreases and simultaneous estimation of (co)variance components of the 33 linear traits and the height at withers is feasible. The program guarantees that the covariance matrix is positive semi-definite. The deceleration step improves the stability of estimates and the convergence in small data sets (Wiggans et al. 2006). However, all traits must be recorded on every animal to apply the method of Misztal et al. (1995). Therefore, only mares with complete data were kept. This resulted in a subset of 977 mares with scores. The pedigree file contained 13592 ancestors (up to 20 generations).

A method to approximate SE of the heritabilities was integrated in the canonical transformation process. 
After convergence of the EM-REML algorithm, the SE of transformed genetic variances was estimated for all 34 traits using the expectation maximization average information REML matrix (Jensen et al. 1997; Johnson \& Thompson 1995). In the next step, we computed a maximal and minimal genetic variance matrix by adding and subtracting the corresponding SEs to the (diagonal) matrix of genetic variances. After back transformation, maximal and minimal genetic variances on the original scale were obtained and from these, we computed maximal and minimal heritabilities using the intermediate phenotypic variance. Finally, the deviation between maximal and minimal heritabilities and the estimated intermediate heritabilities were used to approximate the SE of the heritabilities.

Standard errors for the genetic correlation between the trait $x$ and $y, r_{\mathrm{g}}(x, y)$, were computed using the estimated $r_{\mathrm{g}}(x, y)$, the estimated heritabilities of each trait $\left(h^{2}\right)$ and their respective SE $\left(\sigma_{h^{2}}\right)$, in the following formula (Falconer \& Mackay 1996):

$$
\sigma_{r_{g}}(x, y)=\frac{\left[1-r_{g}{ }^{2}(x, y)\right]}{\sqrt{2}} \sqrt{\frac{\sigma_{h_{x}^{2}} \sigma_{h_{y}^{2}}}{h_{x}^{2} h_{y}^{2}}}
$$

\section{Results and discussion}

\section{Scoring system}

Means and SD of the linear scores are given in Table 3. Mean scores for the linear traits were in the range from -1.5 to 4.8 and the SD of records within linear traits were in the range from 6.7 and 2.7. For most traits, the mean of the assessed population was
Table 3 Mean, standard deviation (SD), skewness and kurtosis of linear type traits and gaits; and heritabilities [standard errors(SE)] in Belgian warmblood horses

\begin{tabular}{lclcrll}
\hline & Mean & SD & Skewness & Kurtosis & $h^{2}$ & SE \\
\hline 1. Height at withers (cm) & 165 & 4 & 0.03 & 2.83 & 0.34 & 0.06 \\
2. Frame & 4.8 & 6.2 & -0.63 & -0.42 & 0.34 & 0.04 \\
3. Condition & 3.7 & 5 & 0.02 & 0.01 & 0.15 & 0.03 \\
4. Head & 0.1 & 4.6 & 0.07 & 0.53 & 0.45 & 0.06 \\
5. Head neck connection & -1.5 & 4.9 & 0.10 & -0.29 & 0.26 & 0.05 \\
6. Length of neck & 0.6 & 5.4 & 0.06 & -0.62 & 0.27 & 0.04 \\
7. Muscularity of neck & 0.2 & 5.3 & 0.03 & -0.32 & 0.31 & 0.05 \\
8. Orientation of neck & 0.4 & 4.7 & 0.02 & -0.26 & 0.24 & 0.05 \\
9. Height of withers & 2.6 & 5.1 & -0.05 & -0.39 & 0.34 & 0.05 \\
10. Length of withers & 1.5 & 5.8 & -0.14 & -0.65 & 0.33 & 0.06 \\
11. Orientation shoulders & 0 & 5.3 & 0.07 & -0.69 & 0.20 & 0.04 \\
12. Length of shoulders & 2.7 & 5.1 & -0.15 & -0.48 & 0.31 & 0.06 \\
13. Length of back & 2.4 & 4.4 & 0.09 & -0.16 & 0.34 & 0.05 \\
14. Back force & -1.2 & 4.6 & 0.17 & 0.49 & 0.55 & 0.07 \\
15. Loins & 1.1 & 5.4 & 0.06 & -0.59 & 0.47 & 0.06 \\
16. Slope of croup & 2 & 5.1 & 0.04 & -0.32 & 0.30 & 0.05 \\
17. Length of croup & 0 & 5.3 & 0.00 & -0.51 & 0.30 & 0.06 \\
18. Muscularity of hind legs & 2.6 & 5.3 & -0.10 & -0.24 & 0.20 & 0.04 \\
19. Position of forelegs 1 & -0.2 & 2.9 & -0.47 & 3.99 & 0.35 & 0.05 \\
20. Position of forelegs 2 & -0.7 & 3.6 & -0.03 & 3.01 & 0.36 & 0.07 \\
21. Position of hind legs & 0.2 & 4.2 & 0.03 & 0.51 & 0.22 & 0.04 \\
22. Position of hocks & 0 & 2.7 & -0.18 & 5.88 & 0.24 & 0.04 \\
23. Development of hocks & 0.9 & 5.2 & 0.15 & -0.55 & 0.22 & 0.05 \\
24. Position of pasterns & 0.3 & 3.7 & 0.29 & 2.05 & 0.25 & 0.05 \\
25. Form of hoof & 0.1 & 4.4 & -0.07 & 0.86 & 0.25 & 0.05 \\
26. Heels & -2.2 & 4.5 & -0.02 & 0.38 & 0.25 & 0.04 \\
27. Volume of legs & -0.1 & 4.5 & 0.02 & -0.16 & 0.46 & 0.07 \\
28. Quality of legs & 2.8 & 5.7 & -0.09 & -0.36 & 0.22 & 0.05 \\
29. Walk stride length & 1.9 & 5.6 & -0.20 & -0.31 & 0.38 & 0.06 \\
30. Walk impulsion & 1.3 & 5.5 & -0.11 & -0.28 & 0.52 & 0.07 \\
31. Walk suppleness & 1.2 & 5.6 & -0.08 & -0.28 & 0.41 & 0.06 \\
32. Trot stride length & 1.9 & 6.2 & -0.14 & -0.41 & 0.47 & 0.05 \\
33. Trot impulsion & 0.5 & 6.7 & -0.12 & -0.59 & 0.36 & 0.05 \\
34. Trot suppleness & 0.9 & 6.5 & -0.07 & -0.44 & 0.33 & 0.04 \\
Mean of all traits & - & - & - & - & 0.32 & 0.05 \\
\hline & & & & & &
\end{tabular}


close to 0 . However, most SD were lower than the expected value of 7 . Skewness of some traits (Table 3) indicated slightly asymmetric distributions (e.g. frame, back force, stride length of walk). Negative kurtosis (Table 3) was observed for many traits indicating a flatter distribution than the normal distribution. On the other hands, height at the withers, position of forelegs and position of hocks have a peaked distribution. However, formal tests (SAS 1985) did not reject the assumption of sampling from a normal distribution for all traits.

Differences in the distribution of scores between appraisers (>100 records) can be observed. Appraiser 1 assigned more positive scores, appraiser 4 more negative scores and appraiser 3 scored the majority of mares with 0 . Scores given by appraiser 2 were well distributed along the scale. The recent start of the system and a lack of formal training of the appraisers might explain the different use of the linear scale. A study of the repeatability between and within appraisers would provide more insight about the lack of similarity. Some of the problems could partially be solved by practical and/or statistical interventions. In dairy cattle, it is common practice to train appraisers to be as similar as possible and often heterogeneity of means and variances due to appraisers are included in the statistical model. In our model, mean differences between appraisers were already modelled and future enhancements of the model should include adjustments for heterogeneity variances Figure 1.

\section{Heritabilities}

Estimates of heritabilities and associated SE are presented in Table 3. Heritabilities ranged from 0.15 to 0.55 with a mean of 0.32. Approximate SEs varied from 0.03 to 0.07 with a mean of 0.05 . These results show that many linear scored traits were moderately heritable with reasonably low SEs. Traits with a heritability over 0.45 were force of the back, loins, the volume of legs, the impulsion of the walk and the length of stride in trot. Seventeen traits had moderate heritability (0.30-0.45), namely the height at withers, frame, head, muscularity of the neck, length of withers, length of the shoulders, length of the back, croup, forelegs, impulsion and suppleness of the trot, stride length and suppleness of the walk.

The lowest estimates of heritability $(<0.25)$ were found for condition, orientation of neck and shoulders, muscularity and position of hind legs, position and volume of hocks and quality of the legs. In general, traits of hind legs and; 'feet' had lower

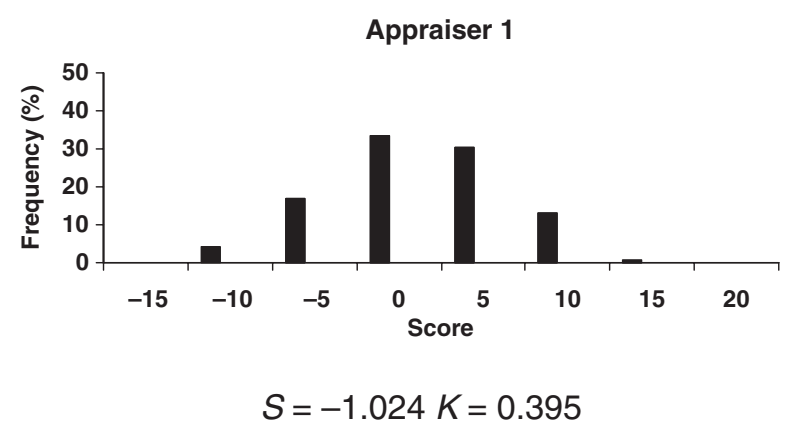

Appraiser 2



Appraiser 3

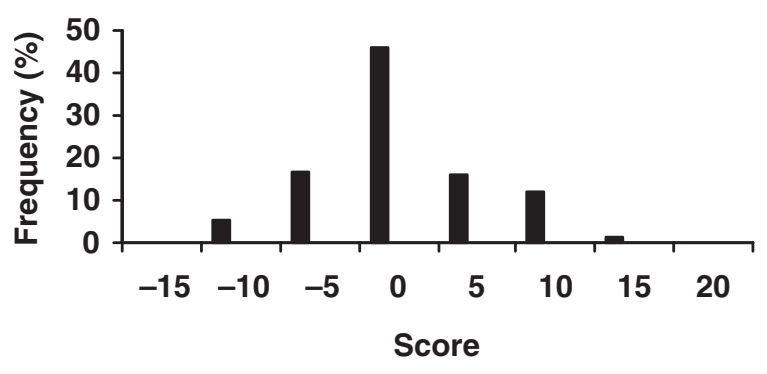

$S=-0.631 K=0.520$

Appraiser 4

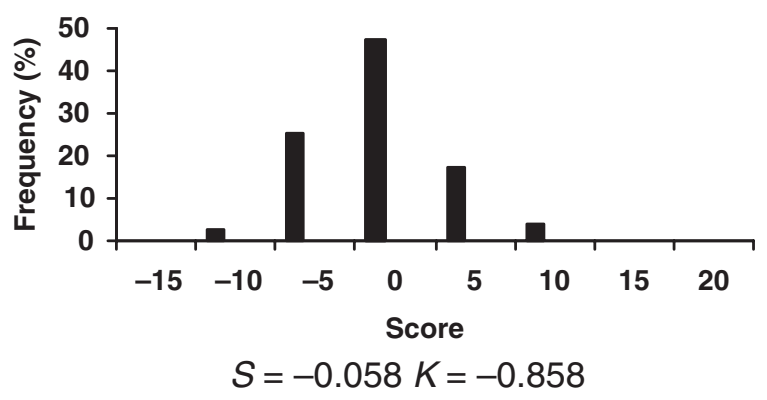

Figure 1 Distribution of scores (proportion of observed mares) for the four major appraisers in the linear scoring system for Belgian warmblood horses. 
heritabilities than others (back, loins, croup, head and withers), with a mean of 0.23 for hind legs and 'feet' traits compared to 0.35 for all the other traits. Our results on the heritability of hind leg traits do not support the general belief of horsemen that leg conformation in horses is highly heritable (Saastamoinen \& Barrey 2000). Similar findings are also often reported in cattle (e.g. Gengler et al. 1997) where feet and leg traits have lower heritability than other conformation traits. Several reasons have been suggested for the low heritabilities of hind leg and feet traits, such as the difficulty of assessment, the training status of the horse or other environmental factors not included in the model (Arnason 1984; Preisinger et al. 1991; Saastamoinen 1993; Saastamoinen et al. 1998).

Heritabilities (and the SEs) for linear scores in the BWP were slightly different from values reported in the literature, nevertheless, the same general tendency was observed as in the study of Van Bergen $\&$ Van Arendonk (1993); Koenen et al. (1995) and Samoré et al. (1997). Differences with other studies could be related to differences between linear systems in term of definitions of traits and scales. Also, the method of estimating variance components was different (e.g. multi-trait versus single trait).

Heritabilities for linear scores in the BWP were lower than for zoometrical measurements (i.e. by metre or reference point on photography). For example, Molina et al. (1999) found heritabilities between 0.35 and 0.95 for seven zoometrical measurements in the Andalusian horse. On the other hand, the mean heritability of linear traits of the BWP was higher than the value of 0.24 , obtained for ranking in 'conformation and gaits contests' (Janssens 1995) and this improvement was achieved without the need for specific or expensive equipment often needed to perform zoometrical measurements.

\section{Genetic correlations}

Genetic correlations ranged between -0.60 and 0.98 (Table 4) with an average SE of 0.10. Genetic correlations for many traits were low and rather close to zero, between -0.30 and 0.30 , indicating virtually independence of these traits. Due to this independence, low correlated selection effects would be expected for many pairs of traits. Some high $(\geq 0.60)$ and moderate correlations (0.40-0.59) were also obtained.

The highest genetic correlations, varying from 0.88 to 0.98 , were found between stride length, suppleness and impulsion within each gait (walk and trot). High positive correlations were also observed between walk and trot. Gaits were moderately to highly correlated with the height at withers and frame. Traits of the trot were positively correlated with muscularity and length of the neck and more moderately with the length of shoulders and the volume of the hocks. The stride length in trot was also moderately correlated with the length of the back. Interpretation of genetic correlations depends in the trait definitions For example, the impulsion, suppleness and stride length increase with taller mares having a more rectangular frame. A short neck with a poor muscularity, light developed hocks and a short back and shoulder is related with low impulsion, short stride length and low suppleness of the trot. Due to the correlations, selection for one of the traits will result in indirect responses in other traits. Consequently, selection for general riding ability could be quite effective. In fact, a long back permits the horse to move smoothly, the neck functions as a balancing tool and long shoulders permit a good development of muscles.

The high correlation (0.87) between the frame and the length of the back is logical because these traits partly overlap. A genetic correlation of 0.61 was found between frame and length of the neck. Lengths of the back and of the neck were also highly correlated (0.72). Lengths of two other traits of the upper line (the withers and the croup) were moderately correlated with the frame. The volume of the hocks was moderately linked with frame and the length of back.

Condition was moderately to highly correlated with muscularity and volume traits. The condition of the horse, reflecting muscularity and overweight, is important. In fact, a good muscularity is necessary to provide sufficient power to get over an obstacle or to perform in dressage. Contrary, a fatty or a bony horse will have some difficulties to perform in competitions. Condition was also highly correlated with the head-neck connection between the head and the neck. Furthermore, a 'large' connection was linked with heavy muscularity of the neck. The muscularity of the neck and the connection between the head and the neck are important for flexing the neck and correct positioning of the neck and head during riding (Van Der Veen 2002).

High and moderate correlations within traits of the shoulders and between shoulders and withers were observed; sloping shoulders and prominent and long withers were related with long shoulders. The importance of shoulders for horse abilities in 
Table 4 Magnitude and direction of genetic correlations between linear traits and height at withers in Belgian warmblood horses

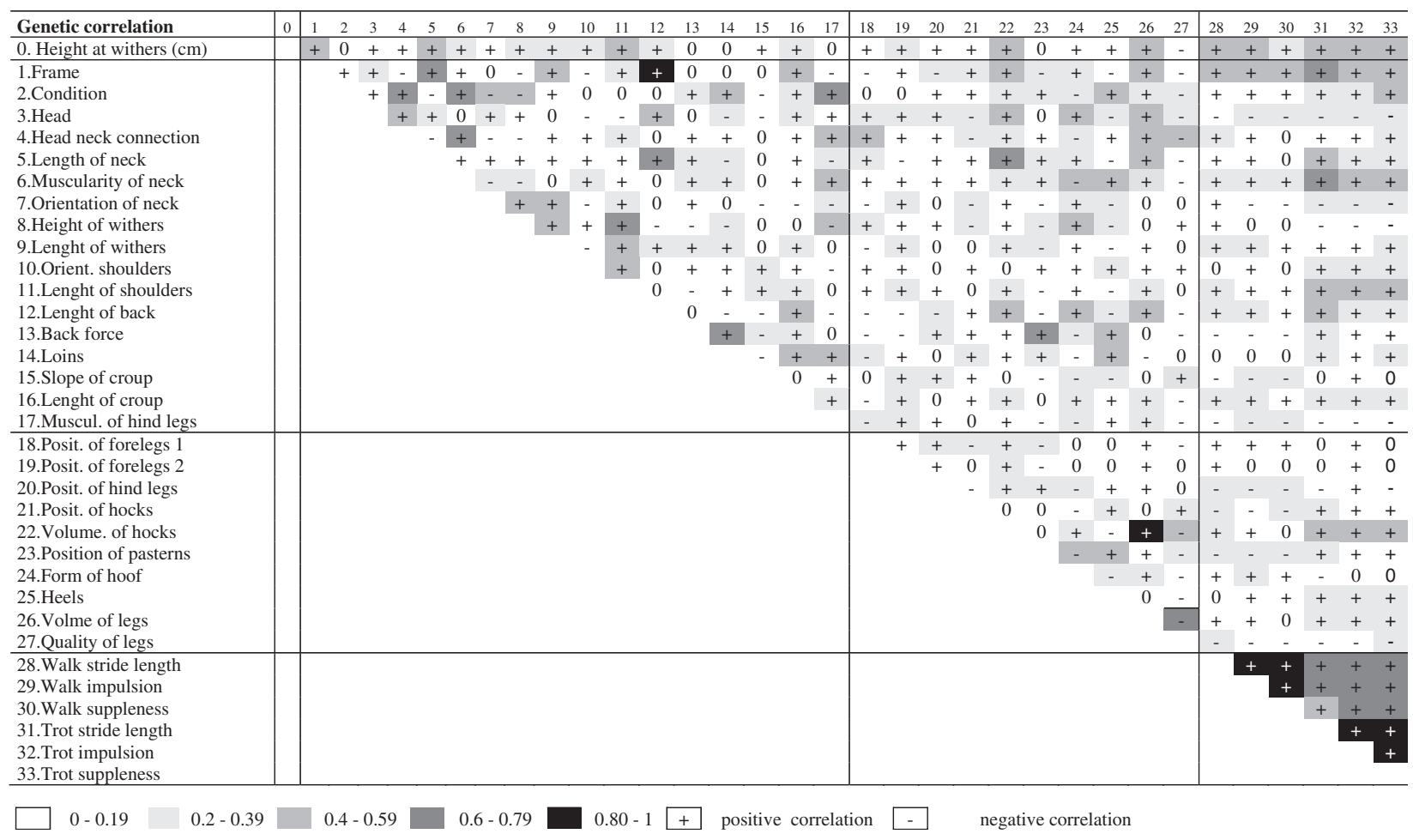

dressage has been recognized (Holmström et al. 1994). A good orientation and length of the shoulders are necessary to have sufficient stride length in the movements and sufficient muscular force. The moderate correlation between these two traits would be favourable for a selection towards a long and sloping shoulder. A prominent withers was also correlated with a long withers, a poor condition, a horizontal and poor muscled neck and a poor muscled hind leg. Even if the withers seem to be less important for riding in a direct way, it is related to other conformation traits.

The neck was associated with other traits. Its muscularity was moderately correlated with the muscularity of hind legs. Its orientation was negatively correlated with its muscularity and positively correlated with the withers. A selection for a long neck would also increase volume of the hocks.

Loins were moderately correlated with the muscularity of hind legs, the length of the croup, the position of forelegs (1) and strongly correlated with the force of the back. The loins are an important part of the body as they link the hindquarters with the forehand and permit the transmission of energy developed by the hind legs. Moreover, the loins were positively correlated with the length of the croup which should permit an optimal stretching of muscles and increases stride length (Van Der Veen 2002). Loins were also positively correlated with the position of forelegs. A bad stance of the forelegs predisposes to a low soundness and a short durability (Stashak 1987). In conclusion, the loins are very important for their direct role in riding abilities and improvement by selection would be facilitated due to their correlations with other conformation traits.

The effectiveness of selection for suppleness of the horse can be increased due to: (i) the high correlation observed between heels and the position of pasterns; (ii) the moderately high correlations between heels and the back force; and (iii) between the length of back and the position of pasterns. In fact, heels and pasterns function as shock absorbers of movements and a correct line of back is also necessary to have supple horses (Van Der Veen 2002).

The correlation between volume and the quality of legs was negative with a value of -0.60 . In fact, a horse with heavy legs can not have blurred legs and inversely. Volume of the legs had a particularly high correlation with volume of the hocks which are 
important for the solidity of legs and for the length of stride in gaits. Volume of the legs was also moderately correlated with length of the back.

In other studies (Koenen et al. 1995; Samoré et al. 1997), linear traits were grouped. For example, linear traits were grouped in traits of the body, traits of legs and traits of the front and different groups were evaluated separately. By doing so, no correlations were obtained between traits belonging to different groups. This results in a loss of information about the possible relationships between traits and consequently, indirect selection responses might be incorrectly evaluated. In this study, we found relative high genetic correlations between traits which would have ended up in different groups, if we had followed the classification of Koenen et al. (1995) and Samoré et al. (1997). For example, frame and gaits, muscularity and orientation of the neck and trot, volume of the hocks and the length and muscularity of the neck, the position of hind legs and the length of the back are pairs that would cross group borders. Therefore, the analysis of all traits jointly was preferred to grouping traits.

A joint analysis of all traits will eventually result in estimated breeding values (EBV) for each linear trait. EBV for separate traits will provide more information to the breeders than aggregated once. On the other hand, too much information could make interpretation difficult and might cause confusion. If required by the studbook or breeders, a principal component analyses could be considered to reduce the information into a limited number of factors (Arnason 1984). Also, indices could be constructed to avoid confusion of producing too much information. However, more important for the success of the system is the collection of more data, so that a larger part of the population is covered.

\section{Conclusion}

The genetic parameters obtained in this study indicate that the linear scoring system is able to generate quantitative and detailed information on distinguishable conformation and gaits traits of the BWP. Magnitudes of heritabilities and genetic correlations indicate that selection is feasible and horse riding abilities could be improved. Even if the current data quality seems adequate, training of appraisers could improve uniformity.

The next step will be to implement a procedure for breeding values estimation. These breeding values will be more effective to support the selection of horses with respect to conformation and gaits.

\section{Acknowledgements}

Authors gratefully acknowledge Dr I. Misztal for providing his computer program MTC that was used in a modified version in this research. Original version of this program is available at ftp://nce.ads.uga.edu. I. Meurrens and the Belgian Warmblood Studbook are acknowledged for providing data. The Belgium Warmblood Studbook is also acknowledges for its financial support. The authors acknowledge the support of VVS (Vlaamse Varken Stamboek) and Flemish Breeding Centre, VFC (both in Oosterzele, Belgium). N. Gengler, who is Research Associate of the National Fund for Scientific Research (Brussels, Belgium), acknowledges this support. The National Fund for Scientific Research supported also this research by grants F.4552.05 and 2.4507.02F(2).

\section{References}

Arnason Th. (1984) Genetic studies in conformation and performance of Icelandic toelter horses. Acta Agric. Scand., 34, 409-427.

Falconer D.S., Mackay T.F.C. (1996) Genetic and environmental correlations. In: Longman (ed.), Introduction to Quantitative Genetics, 4th edn., Longman, Essex, England, pp. 315-316.

Forest A. (1996) La conformation d'un cheval. Son importance avant l'achat en fonction d'un service recherché et pour le choix des reproducteurs. In: Le Cheval, mon compagnon (ed.), Proceeding of the 7th Symposium of Council Animal Production of Quebec, Saint-Hyacinthe, Quebec, pp. 4-13.

Gengler N., Wiggans G.R., Wright J.R., Norman H.D., Wolfe C.W. (1997) Estimation of (co) variance for Jersey type trait using a repeatability model. J. Dairy Sci., 80, 1801-1806.

Holmström M., Fredricson I., Drevemo S. (1994) Biokinematics effect of collection in the elite dressage horse trot. In: M. Holmström (ed.), Quantitatie Studies on Conformation and Trotting Gaits in the Swedish Warmblood Riding Horse. Phd Thesis, Agricultural University of Sweden, Uppsala.

Janssens S. (1995) Sportpaarden: Overzicht Berekeningen. Internal report. Centrum Huisdieren Genetica and Selectie, Katholieke Universiteit Leuven, Belgium, pp. $48-50,68-73$.

Jensen J., Mantysaari E., Madsen P., Thompson R. (1997) Residual maximum likelihood estimation of (co)variance components in multivariate mixed linear models using average information. Indian Soc. Agric. Stat., 49, 215-236.

Johnson D.L., Thompson R. (1995) Restricted maximum likelihood estimation of variance components for 
univariate animal models using sparse matrix techniques and average information. J. Dairy Sci., 78, 449456.

Koenen E.P.C., Van Veldhuizen A.E., Brascamp E.W. (1995) Genetic parameters of linear scored conformation traits and their relation to dressage and showjumping performance in the Dutch Warmblood Riding Horse population. Livest. Prod. Sci., 43, 85-94.

Mawdsley A., Kelly E.P., Smith F.H., Brophy P.O. (1996) Linear assessment of the Thoroughbred horse: an approach to conformation evaluation. Equine Vet. J., 28, 461-467.

Misztal I., Weigel K., Lawlor T.J. (1995) Approximation of estimates of ( $\mathrm{CO}$ ) variance components with multiple trait restricted maximum likelihood by multiple diagonalization for more than one random effect. J. Diary Sci., 78, 1862-1872.

Molina A., Valera M., Dos Santos R., Rodero A. (1999) Genetic parameters of morphofunctional traits in Andalusian horse. Livest. Prod. Sci., 60, 295-303.

Preisinger R., Wilkens J., Kalm E. (1991) Estimation of genetic parameters and breeding values for conformation traits for foals and mares in the Trakhener population and their practical implications. Livest. Prod. Sci., 29, 77-86.

Saastamoinen M.T. (1993) Effect of month of birth, month of judging and sex of the horse on conformation score, size and growth of young horses in Finland. In: European Association for Animal Production (ed.), Horse breeding and Production in Cold Climatic Regions. Reykjavik, Iceland.

Saastamoinen M.T., Barrey E. (2000) Conformation, locomotion and physiological traits. In: A.T. Bowling,
A. Ruvinski (eds), The genetic of the horse. CAB International, United of Kingdom, pp. 439-472.

Saastamoinen M.T., Suontama M., Ojala M. (1998) Environmental factors affecting conformation and correlations between conformation traits in the Finnhorse trotter. In: Book of abstract of European Association for Animal Production (ed.), Proceeding of the 49th European Association for Animal Production. Warsaw, Poland.

Samoré A.B., Pagnacco G., Miglior F. (1997) Genetic parameters and breeding value for linear type traits in the Haflinger horse. Livest. Prod. Sci., 52, 105-111.

SAS (1985) SAS Users Guide: Statistics. Version 5. SAS Institute Inc., Cary, USA.

Stashak T.S. (1987) The Relationship Between Conformation and Lameness In Adam's Lameness in Horse. Lea \& Febiger, Philadelphia, pp 71-99.

Thompson J.R., Lee K.L., Freeman A.E. (1983) Evaluation of a linearized type appraisal system for Holstein cattle. J. Dairy Sci., 66, 325-333.

Van Bergen H.M.M., Van Arendonk J.A.M. (1993) Genetic parameters for linear type traits in Shetland ponies. Livest. Prod. Sci., 36, 273-284.

Van Der Veen G. (2002) Het Paard in Paartjes. 4th edn. Baarn, Tirion uitgevers BV.

Van Vleck L.D. (1993) Selection Index and Introduction to Mixed Model Methods. Departement of Animal Science, University of Nebraska, Lincoln, Library of Congress Cataloging In Publication Data.

Wiggans G.R., Thornton L.L.M., Neitzel R.R., Gengler N. (2006) Genetic parameters and evaluation of rear legs (rear view) for Brown Swiss and Guernseys. J. Dairy Sci., 89, 4895-4900. 